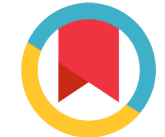

Check for updates

\title{
Effect of IgG from multiple sclerosis patients on amidolytic activity of coagulation and anticoagulation factors of hemostasis
}

\section{Katrii T.B. ${ }^{1 *}$, Shandyuk V.Yu. ${ }^{2}$, Vovk T.B. ${ }^{1}$, Halenova T.I. ${ }^{1}$, Raksha N.G. ${ }^{1}$, Shershnov O.V. ${ }^{3}$, Melnyk V.S. ${ }^{2,3}$, Savchuk O.M. ${ }^{1}$, Ostapchenko L.I. ${ }^{1}$}

\author{
${ }^{1}$ Educational and Scientific Center (Institute of Biology and Medicine), Taras Shevchenko \\ National University of Kyiv, Ukraine \\ ${ }^{2}$ Bogomolets National Medical University, Kyiv, Ukraine \\ ${ }^{3}$ llaya Medical Company (A.A. PARTNERS LLC)
}

*For correspondence:

tetiana.katrii@gmail.com

Competing interests: The authors declare that no competing interests exist.

Received: 24 June 2017

Accepted: 11 August 2017

Published: 16 August 2017

Copyright The Author(s) 2017. This article is published with open access by BioMedPress (BMP).

This article is distributed under the terms of the Creative Commons Attribution License (CC-BY 4.0) which permits any use, distribution, and reproduction in any medium, provided the original author(s) and the source are credited.

\section{Abstract}

Background: Immunoglobulin G (IgG) is a major immunoglobulin (Ig) in blood that accumulates to a greater extent in the bloodstream of patients impacted by neuroimmunological disorders such as multiple sclerosis (MS). The aim of this study was to determine the effect of IgG obtained from MS patients on the amidolytic activity of coagulation and on anticoagulation factors, and to compare those effects to the effects of IgG from healthy donors. Methods: Spectrophotometric hydrolysis of specific chromogenic substrate by key haemostasis factors was examined. Results: Our study shows that unlike healthy individuals, patients suffering from MS express IgG which enhances the amidolytic activity of thrombin and protein $\mathrm{C}$, but inhibits the activity of factor Xa. Conclusion: Our study shows that IgG and coagulation factors, indeed, interact with each other. IgG may be key mediators of neuroinflammation and, therefore, may serve as a potential target for therapeutic strategies for MS and other neuroimmunological diseases.

\section{Keywords}

Amidolytic activity, Factor Xa, IgG, Multiple sclerosis, Protein C, Thrombin 


\section{Introduction}

Multiple sclerosis (MS) is an autoimmune disorder of the central nervous system mediated by different molecular and cellular immune components, which lead to disseminated inflammatory lesions within the brain parenchyma and potential brain damage (Bhat and Steinman, 2009; Göbel et al., 2016a). The pathogenesis of MS has long been imparted to self-reactive $T$ cells though $B$ cells have also recently been found to play an important role in the development of MS (Disanto et al., 2012; Sospedra and Martin, 2005). Furthermore, it has been demonstrated that innate immunity plays a pivotal role in the initial pathogenesis as well as in advanced stages of MS (Gandhi et al., 2010; Mayo et al., 2012; Weiner, 2008).

Recent studies suggest that factors of the coagulation cascade traditionally described as an entirely separate entity of the immune system might also be involved in MS development (Delvaeye and Conway, 2009). Moreover, several extensive studies have demonstrated the association of disorders of hemostasis cascades and MS. Recent data point to a role of both the extrinsic and the intrinsic coagulation systems.

One factor that has been described within chronic active MS plaques is tissue factor, a glycoprotein considered to be the initiator of the extrinsic coagulation cascade leading to the activation of factor $X$ directly or indirectly through activation of factor IX (Han et al., 2008). Activation of factor $X$ mediates the cleavage of prothrombin to thrombin that is able to cleave fibrinogen to fibrin. Interestingly, both fibrinogen deposition and thrombin activation have been reported in human MS lesions or in animal models (Adams et al., 2007; Davalos et al., 2014; Gverić et al., 2003). Furthermore, degradation products of fibrinogen and fibrin (e.g. fibrinopeptide $A$ and D-dimer) have been shown to be significantly upregulated in individuals suffering from MS, while fibrinogen levels were found to be unaltered (Aksungar et al., 2008; Ehling et al., 2011; Liguori et al., 2014). These alterations were also significantly increased in blood samples of MS patients compared to healthy controls (Göbel et al., 2016b).

Overall, data from the literature suggest that inhibition of components from both the intrinsic and extrinsic coagulation systems can protect against inflammatory neurodegeneration. For instance, multiple findings support the prominent role of the coagulation system in the development of MS (Aksungar et al., 2008; Han et al., 2008). Nevertheless, to date, the mechanisms of regulation of coagulation factors in blood of individuals suffering from neuroinflammatory disorders (especially MS) have not been evaluated in detail. 


\section{Materials-Methods}

Blood plasma samples were taken from 35 healthy donors and 20 patients with MS. Patients were hospitalized in the Neurological Department of Hospital №4 (Kyiv, Ukraine). All donors and patients (or their respective relatives) were informed about the clinical research protocol. Informed consent was obtained in accordance with the Declaration of Helsinki. The clinical research protocol was approved by the Ethics Committees of the ESC (Institute of Biology and Medicine) of Kyiv, Ukraine. Fasting blood samples were collected from the cubital vein of all patients on the first day of hospitalization. Blood was collected into $3.8 \%$ sodium citrate solution (at a ratio of $9: 1$ ).

IgG was separated by affinity chromatography on protein A sepharose. One ml of blood plasma was applied to the column of protein A Sepharose (total volume of the column was $5 \mathrm{ml}$ ). Non-specific bound proteins were washed with $50 \mathrm{mM}$ Tris- $\mathrm{HCl}$ buffer containing $130 \mathrm{mM} \mathrm{NaCl}, \mathrm{pH}$ 7.4. Elution was performed using $0.1 \mathrm{M}$ glycine- $\mathrm{HCl}$ buffer, $\mathrm{pH}$ 2.2. The purity of separated IgG fractions was controlled by $7.5 \%$ PAGE using the following protein standards: myosin (200 kDa), b-galactosidase (116 kDa), phosphorylase b (97 kDa), albumin $(66.2 \mathrm{kDa})$ and ovalbumin (45 kDa). Gels were stained with $0.125 \%$ solution of Coomassie Brilliant Blue G-250 in 25\% isopropanol and $10 \%$ acetic acid. The concentration of the separated IgG was measured by spectrophotometer (Bio-Rad, Hercules, CA).

In order to investigate the influence of IgG on hemostasis in vitro experiments were conducted using a standard set of reagents; "Renam" Russia reagents were used according to the manufacturer's instructions. IgG obtained from patients with MS as well as from healthy donors were applied to a mixture in two concentrations: 100 and $300 \mu \mathrm{g} / \mathrm{ml}$.

To examine the influence of IgG on key hemostasis enzymes (thrombin and Factor $\mathrm{Xa}$ ) in vitro experiments were performed. The following mixture was prepared as follows: $25 \mu$ l of enzyme was mixed with $50 \mathrm{mM}$ Tris- $\mathrm{HCl}$ containing $130 \mathrm{mM} \mathrm{NaCl}, \mathrm{pH} 7.4$ and then lgG was added. After $5 \mathrm{~min}$ incubation at $37^{\circ} \mathrm{C}$, the corresponding specific chromogenic substrate (in a final concentration of $0.3 \mathrm{mM}$ ) was added to the mixture (Table 1 ).

To examine the influence of IgG on hemostasis enzymes (prothrombin and proenzyme of Protein C) during their zymogen activation the following mixture was prepared as follows: $25 \mu \mathrm{l}$ of healthy donor plasma was mixed with $50 \mathrm{mM}$ Tris- $\mathrm{HCl}$ containing $130 \mathrm{mM} \mathrm{NaCl}, \mathrm{pH} 7.4$, then with $25 \mu \mathrm{l}$ of corresponding activators for plasma zymogens, and finally lgG was added (Table 1). After 5 min incubation at $37^{\circ} \mathrm{C}$, the corresponding specific chromogenic substrate (in a final concentration of $0.3 \mathrm{mM}$ ) was added to the mixture (Table 1 ).

Absorption was measured in two-wave mode at the primary 405 and reference $492 \mathrm{~nm}$ wavelengths in a microplate spectrophotometer (QuantTM, BioTek 
Instruments, Inc) for 60 minutes. The activity of the evaluated process was proportional to color intensity following release of $p$-nitroaniline from the chromogenic substrate. The control sample contained the same components but with an equal volume of $50 \mathrm{mM}$ Tris- $\mathrm{HCl}$ buffer containing $130 \mathrm{mM} \mathrm{NaCl}$, $\mathrm{pH} 7.4$, instead of $\mathrm{lgG}$.

Table 1. Experimental design

\begin{tabular}{|c|c|c|}
\hline Evaluations & Activator & $\begin{array}{c}\text { Corresponding } \\
\text { chromogenic } \\
\text { substrate }\end{array}$ \\
\hline $\begin{array}{c}\text { Activation of protein C } \\
\text { zymogen in plasma }\end{array}$ & $\begin{array}{c}\text { Derived from the venom } \\
\text { Agkistrodon blomhoffi } \\
\text { ussuriensis (Renam, Russia) }\end{array}$ & $\mathrm{S} 2366$ \\
\hline $\begin{array}{c}\text { Activation of thrombin } \\
\text { zymogen in plasma }\end{array}$ & $\begin{array}{c}\text { Ecamylin (Technology- } \\
\text { Standard, Russia) }\end{array}$ & $\mathrm{S} 2238$ \\
\hline Activity of thrombin & - & $\mathrm{S} 2238$ \\
\hline Activity of factor Xa & $\begin{array}{c}\text { Derived from the Russell viper } \\
\text { venom (Renam, Russia) }\end{array}$ & $\mathrm{S} 2765$ \\
\hline
\end{tabular}

Statistical analysis of the experimental results was performed in the Origin program. Mean (M) and standard deviation (SD) were calculated for each group. A statistically significant difference was set at $P<0.05$. Statistical analysis of electrophoregrams was performed in the TotalLab 2. 01 program.

\section{Results}

In this study, IgG from MS patients was shown to have the ability to affect the amidolytic activity of hemostasis enzymes such as thrombin, factor $X$ and protein C. The effect of IgG from blood plasma of the MS patients was significantly greater compared to the effect of $\mathrm{IgG}$ from healthy donors.

Thrombin is a protease in blood that facilitates blood clotting by converting fibrinogen to fibrin. There was an increase of amidolytic activity of thrombin under influence of fractions of $\mathrm{lgG}$ in both concentration of 100 and $300 \mu \mathrm{g} / \mathrm{ml}$ (Fig. 1). In normal conditions without lgG in mixture, the level of amidolytic thrombin activity was equal to $0.485 \pm 0.013$ relative units (r.u.). After applying IgG from healthy donors to the mixture, the level of thrombin activity after 60 minutes of incubation was $45 \%$ higher (for the $100 \mu \mathrm{g} / \mathrm{ml} \mathrm{lgG}$ concentration) and $35 \%$ higher (for the $300 \mu \mathrm{g} / \mathrm{ml} \mathrm{lgG}$ concentration). However, IgG obtained from blood plasma of patients with MS induced a stronger effect, after application of $\lg G$ from MS patients. Thus, IgG from MS patients, at a concentration of $100 \mathrm{\mu g} / \mathrm{ml}$, increased thrombin activity by $30 \%$; at a concentration of $300 \mu \mathrm{g} / \mathrm{ml}$, lgG from MS patients increased the activity by $58 \%$ 
(Fig. 1). In comparison to the effect of $\operatorname{lgG}$ from healthy donors on thrombin activity, IgG from MS patients (at the same concentration of $300 \mu \mathrm{g} / \mathrm{ml}$ ) was $17 \%$ greater.

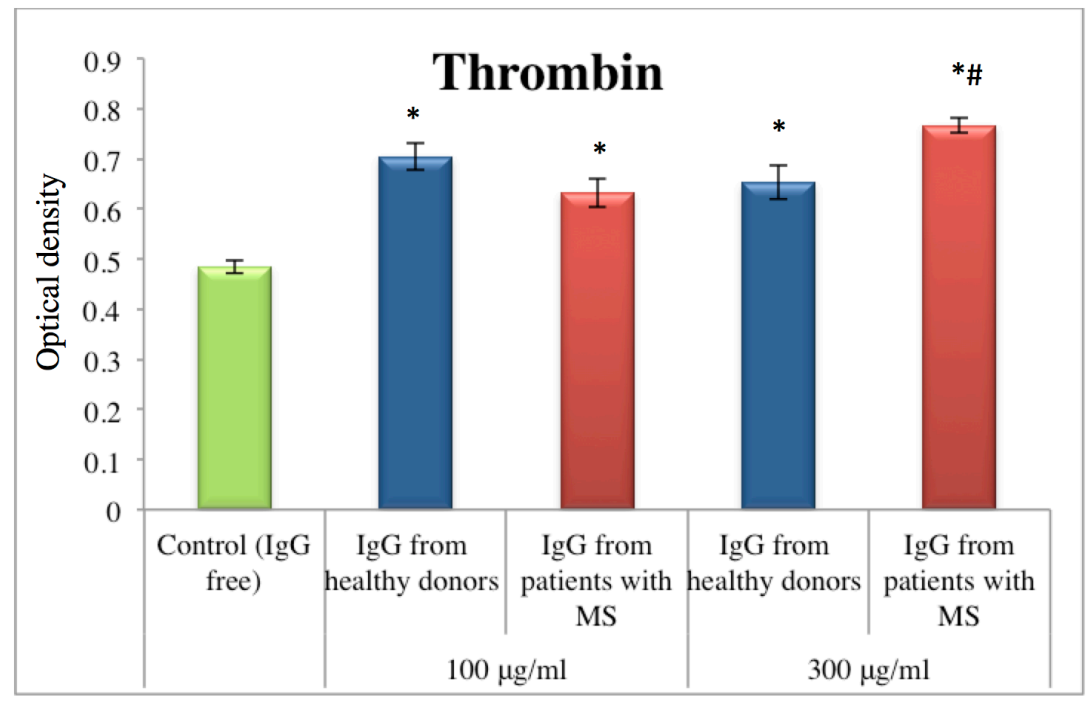

Figure 1. Effect of IgG from blood plasma of MS patients on the amidolytic activity of thrombin (healthy donors, $n=35$; MS patients, $n=20$ ). (*) statistical significance compared to control (IgG free); (\#) statistical significance compared to $\lg G$ from healthy donors (at the indicated lgG concentrations).

The opposite trend was observed for factor Xa (also known as the eponym Stuart-Prower factor). Unlike IgG from healthy donors, IgG from MS patients inhibited amidolytic activity of factor Xa. For example, IgG from MS patients (at a concentration of $100 \mu \mathrm{g} / \mathrm{ml}$ ) inhibited factor Xa activity by $23 \%$. At a concentration of $300 \mu \mathrm{g} / \mathrm{ml}$, lgG from MS patients inhibited factor Xa activity by $5 \%$ (Fig. 2). Overall, compared to the effect of IgG from healthy donors, the inhibitory effect of lgG from MS patients was $28 \%$ greater (at the $100 \mu \mathrm{g} / \mathrm{ml} \mathrm{lgG}$ concentration) and $14 \%$ greater (at the $300 \mu \mathrm{g} / \mathrm{ml} \mathrm{lgG}$ concentration).

Next, the amidolytic activity of hemostasis enzymes was measured after activation of the corresponding zymogens in blood plasma. Activation was achieved by addition of the specific endogenic activators in medium (Table 1). This technique can help address questions about specificity of the tested reactions. The effect of IgG in the blood plasma remains unclear. To address this, we applied the lgG from healthy donors and the corresponding activators instead of key enzymes in the medium during incubation. 


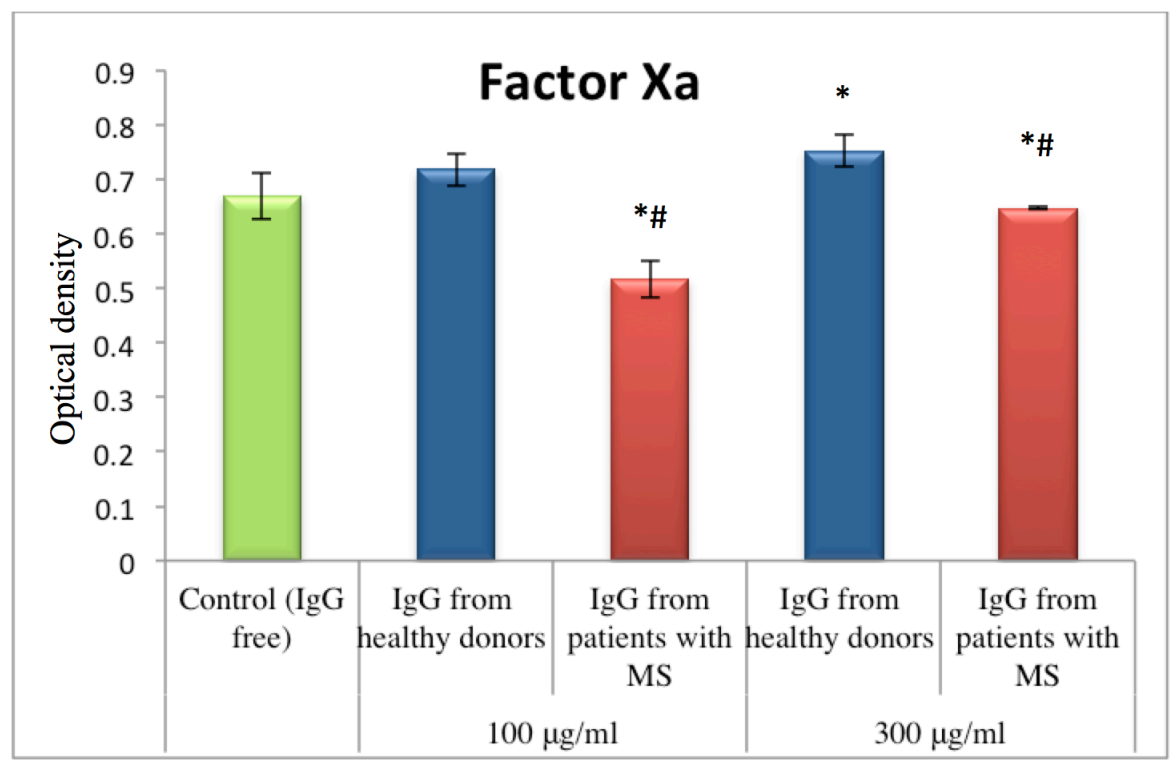

Figure 2. Effect of IgG from blood plasma of MS patients on the amidolytic activity of factor $X a$ (healthy donors, $n=35$; MS patients, $n=20$ ). * statistical significance compared to control (lgG free). \# statistical significance compared to IgG of healthy donors (at the indicated IgG concentrations)

The results showed an effect of IgG on thrombin followed by prothrombin activation in plasma under the influence of activator derived from the venom Echis multisquamatus (ecamylin). Thus, IgG obtained from MS patients as well as IgG from healthy donors both showed activation of amidolytic activity of thrombin after its activation of prothrombin in plasma. In the control probe without IgG, the level of amidolytic thrombin activity was equal to $0.458 \pm 0.021$ r.u. After applying healthy donor IgG to the mixture, the level of thrombin activity after 60 minutes of incubation was 42\% (for the $100 \mu \mathrm{g} / \mathrm{ml} \mathrm{lgG}$ concentration) and 22\% (for the $300 \mu \mathrm{g} / \mathrm{ml} \mathrm{lgG}$ concentration) greater compared to the control. Meanwhile, the level of thrombin activity after applying IgG from MS patients was $49 \%$ (for the $100 \mu \mathrm{g} / \mathrm{ml} \mathrm{lgG}$ concentration) and $32 \%$ (for the $300 \mu \mathrm{g} / \mathrm{ml} \mathrm{lgG}$ concentration) greater compared to the control (Fig. 3).

Protein C, also known as autoprothrombin IIA and blood coagulation factor XIV, plays an important role in regulating anticoagulation, inflammation and cell death, and in maintaining the permeability of blood vessel walls. The amidolytic activity of Protein $\mathrm{C}$ was measured in plasma after activation of its zymogen under the influence of activator derived from the venom Agkistrodon blomhoffi ussuriensis. A statistically significant difference was observed under the influence of MS-derived lgG at a concentration of $300 \mu \mathrm{g} / \mathrm{ml}$. The level of Protein C activation was elevated by $21 \%$ compared to the control (Fig. 4). 


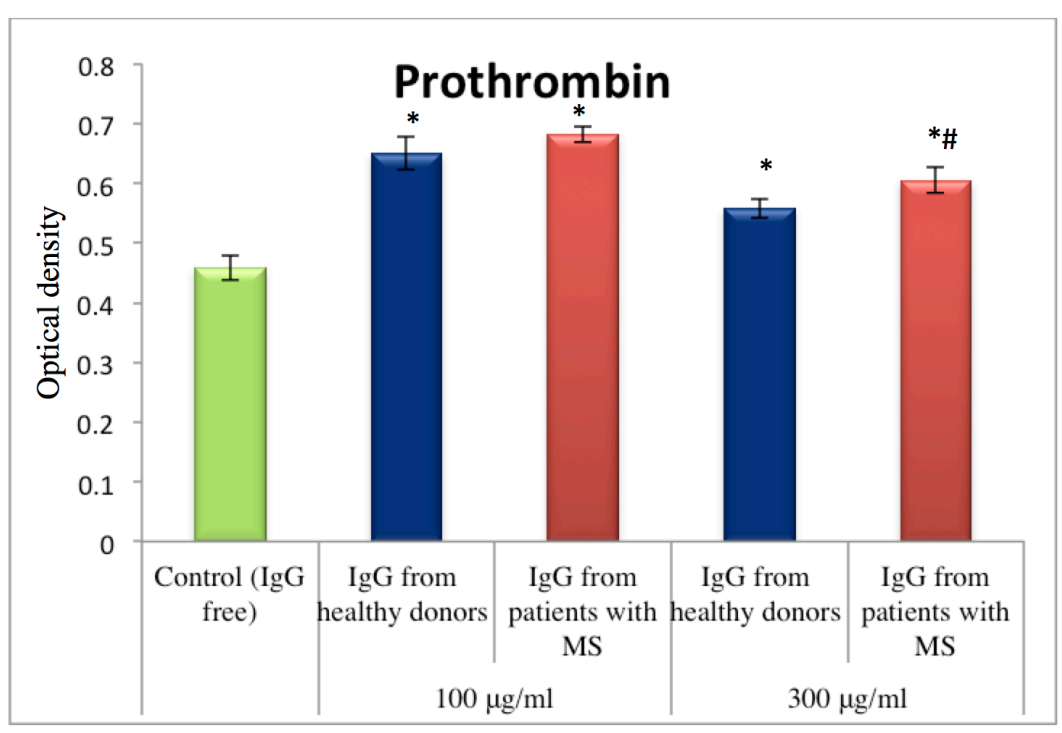

Figure 3. Effect of IgG from blood plasma of MS patients on the amidolytic activity of thrombin after activation of prothrombin (healthy donors, $\mathbf{n}=$ 35; MS patients, $\mathbf{n}=\mathbf{2 0}$ ). ( $\left.{ }^{\star}\right)$ statistical significance compared to control (lgG free), (\#) statistical significance compared to effect of IgG from healthy donors (at the indicated IgG concentrations)

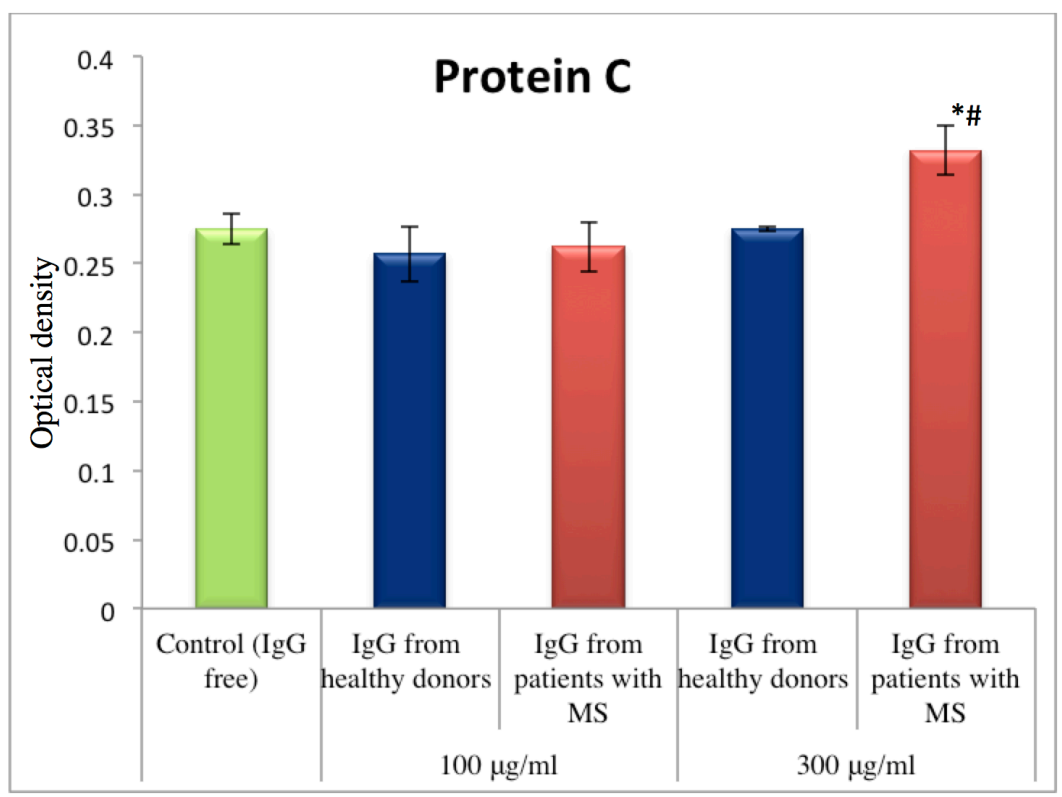

Figure 4. Effect of IgG from blood plasma of MS patients on the amidolytic activity of Protein $\mathbf{C}$ after activation of its zymogen (healthy donors, $n=$ 35; MS patients, $\mathbf{n}=\mathbf{2 0}$ ). ( $\left.{ }^{\star}\right)$ statistical significance compared to control ( $\lg G$ free), (\#) statistical significance compared to $\lg G$ from healthy donors (at the indicated $\lg G$ concentrations) 


\section{Discussion}

In this study, we showed that the amidolytic activity of coagulation as well as anticoagulation factors were altered under the influence of IgG obtained from patients with MS (a prototypic neuroinflammatory disease). As comparison, the effect of IgG obtained from healthy donors was also evaluated. For the most part, an increase of amidolytic activity for both thrombin and protein $C$ were observed. However, an inhibition of factor Xa activity was also observed. According to the literature, prothrombin and factor Xa are strongly elevated in individuals suffering from MS (Bhat and Steinman, 2009). Prothrombin and other hemostasis factors have been described to potentially enhance inflammation in artherosclerotic plaques, sepsis, endotoxemia and encephalomyelitis (Borissoff et al., 2011; Schoenmakers et al., 2005; Strukova, 2001). We showed an effect of IgG on the activity of coagulation as well as anticoagulation factors.

Although the role of hemostasis enzymes in the interactions with IgG need to be further studied, the described coagulation factors may represent key mediators in neuroinflammation (Bhat and Steinman, 2009; Göbel et al., 2016 b). Accordingly, the interactions between IgG and coagulation factors may provide new targets for the development of future therapeutic strategies for MS and possibly other neuroimmunological diseases. Moreover, they may serve as possible biomarkers for disease monitoring.

\section{Conclusion}

In this study, we demonstrated that IgG is able to exert an effect on the enzymes of hemostasis system. There was an observed elevation of amidolytic activity of thrombin, as well as thrombin and protein $C$ activated from their zymogens in blood plasma, after addition of $\lg$ from MS patients (at a concentration of $300 \mu \mathrm{g} / \mathrm{ml}$ ). The influence of MS-derived lgG fractions (at 100 and $300 \mu \mathrm{g} / \mathrm{ml}$ concentrations) on thrombin, in a system without plasma or after its activation in plasma, provide evidence of a potentially direct impact of $\lg$ on thrombin. These revelations may influence future therapeutic strategies for MS. Moreover, inhibition of amidolytic activity of factor Xa was also observed. However, correlation between the level of inhibition and $\lg G$ concentration was absent. IgG obtained from healthy donors also affected the tested reactions in some measure too. A mechanism of concurrent inhibition might be occurring, but future investigations are needed to evaluate that. 


\section{Biomedical \\ Research \& Therapy}

ISSN: $2198-4093$

\section{Abbreviations}

IgG: Immunoglobulin G

MS: multiple sclerosis

\section{Author Contribution}

All authors contributed in manuscript preparation. Katrii T.B., Shandyuk V.Yu. obtained data and analyzed it. Vovk T.B., Halenova T.I., Raksha N.G. interpreted of data analysis. Katrii T.B. designed of figures. Shershnov O.V., Melnyk V.S, Savchuk O.M., Ostapchenko L.I. performed designed the study. All authors drafted the first version and approve the final draft. 


\section{References}

Adams, R.A., Bauer, J., Flick, M.J., Sikorski, S.L., Nuriel, T., Lassmann, H., Degen, J.L., and Akassoglou, K. (2007). The fibrin-derived Y377-395 peptide inhibits microglia activation and suppresses relapsing paralysis in central nervous system autoimmune disease. Journal of Experimental Medicine 204, 571-582.

Aksungar, F.B., Topkaya, A.E., Yildiz, Z., Sahin, S., and Turk, U. (2008). Coagulation status and biochemical and inflammatory markers in multiple sclerosis. Journal of Clinical Neuroscience 15, 393-397.

Bhat, R., and Steinman, L. (2009). Innate and adaptive autoimmunity directed to the central nervous system. Neuron 64, 123-132.

Borissoff, J.I., Spronk, H.M., and ten Cate, H. (2011). The hemostatic system as a modulator of atherosclerosis. New England Journal of Medicine 364, 1746-1760.

Davalos, D., Baeten, K.M., Whitney, M.A., Mullins, E.S., Friedman, B., Olson, E.S., Ryu, J.K., Smirnoff, D.S., Petersen, M.A., and Bedard, C. (2014). Early detection of thrombin activity in neuroinflammatory disease. Annals of neurology 75, 303-308.

Delvaeye, M., and Conway, E.M. (2009). Coagulation and innate immune responses: can we view them separately? Blood 114, 2367-2374.

Disanto, G., Morahan, J., Barnett, M., Giovannoni, G., and Ramagopalan, S. (2012). The evidence for a role of B cells in multiple sclerosis. Neurology 78, 823-832.

Ehling, R., Di Pauli, F., Lackner, P., Kuenz, B., Santner, W., Lutterotti, A., Gneiss, C., Hegen, H., Schocke, M., and Deisenhammer, F. (2011). Fibrinogen is not elevated in the cerebrospinal fluid of patients with multiple sclerosis. Fluids and Barriers of the CNS 8, 25.

Gandhi, R., Laroni, A., and Weiner, H.L. (2010). Role of the innate immune system in the pathogenesis of multiple sclerosis. Journal of neuroimmunology 221, 7-14.

Göbel, K., Kraft, P., Pankratz, S., Gross, C.C., Korsukewitz, C., Kwiecien, R., Mesters, R., Kehrel, B.E., Wiendl, H., and Kleinschnitz, C. (2016a). Prothrombin and factor X are elevated in multiple sclerosis patients. Annals of neurology 80, 946-951.

Göbel, K., Pankratz, S., Asaridou, C.-M., Herrmann, A.M., Bittner, S., Merker, M., Ruck, T., Glumm, S., Langhauser, F., and Kraft, P. (2016b). Blood coagulation factor XII drives adaptive immunity during neuroinflammation via CD87-mediated modulation of dendritic cells. Nature communications 7, 11626.

Gverić, D., Herrera, B., Petzold, A., Lawrence, D.A., and Cuzner, M.L. (2003). Impaired fibrinolysis in multiple sclerosis: a role for tissue plasminogen activator inhibitors. Brain 126, 1590-1598.

Han, M.H., Hwang, S.-I., Roy, D.B., Lundgren, D.H., Price, J.V., Ousman, S.S., Fernald, G.H., Gerlitz, B., Robinson, W.H., and Baranzini, S.E. (2008). Proteomic analysis of active multiple sclerosis lesions reveals therapeutic targets. Nature 451, 1076.

Liguori, M., Qualtieri, A., Tortorella, C., Direnzo, V., Bagala, A., Mastrapasqua, M., Spadafora, P., and Trojano, M. (2014). Proteomic profiling in multiple sclerosis clinical courses reveals potential biomarkers of neurodegeneration. PloS one 9, e103984.

Mayo, L., Quintana, F.J., and Weiner, H.L. (2012). The innate immune system in demyelinating disease. Immunological reviews 248, 170-187.

Schoenmakers, S.H., Reitsma, P.H., and Spek, C.A. (2005). Blood coagulation factors as inflammatory mediators. Blood Cells, Molecules, and Diseases 34, 30-37. 


\section{Biomedical} Research \& Therapy
ISSN: $2198-4093$

www.bmrat.org

Sospedra, M., and Martin, R. (2005). Immunology of multiple sclerosis. Annu Rev Immunol 23, 683-747.

Strukova, S. (2001). Thrombin as a regulator of inflammation and reparative processes in tissues. Biochemistry (Moscow) 66, 8-18.

Weiner, H.L. (2008). A shift from adaptive to innate immunity: a potential mechanism of disease progression in multiple sclerosis. Journal of neurology 255, 3-11. 